\title{
REGULATION AND DEVELOPMENT OF TERRITORIES IN LAND PROPERTIES - REGULATORY ASPECTS AND PROBLEMS
}

\author{
G.Velkovska* \\ Faculty of Economics, Trakia University, Stara Zagora, Bulgaria
}

\begin{abstract}
The regulation of territories inland properties is a specific technological and legal process, which is carried out through the tools of detailed spatial planning. The detailed development plans regulate streets, neighborhoods, and land properties for construction and for meeting other needs without construction of the respective land properties. The task of the settlement is to prepare the necessary conditions on the territory in order to make possible the realization of the construction itself. In this sense, it can be said that both processes are interrelated, but the leading and necessary role of the process of settlement of land in the land. The unifying moment in both processes is their legal regulation, which takes into account in detail the specifics of the specific territories and on this basis approves the specific parameters of the settlement and construction.

The settlement of a land property determines its boundaries to a street, road or alley (face of the property) and to the neighboring land properties (side and to the bottom of the property). The settlement of each property also determines the type, manner, character, lines and value indicators of construction in the land property. The purpose of the article is to present and analyze some normative aspects and problems related to the regulation and construction of territories in land properties.

The main research method used in the article is normative analysis. On the basis of the performed normative analysis some imperfections of the normative regulation are summarized and as a final result way for overcoming these imperfections are suggested in the conclusion. For the purposes of the analysis, opinions of authors working in this field were also used.
\end{abstract}

Keywords: territory, land property, development plan, settlement, construction, law, parameters, regulated land property

\section{INTRODUCTION}

The smallest territorial unit in the structure of the settlement, which is subject to spatial planning, is the regulated land property [5]. With the settlement of each land property, according to the requirements of the Spatial Planning Act, its boundaries to a street, road or alley or to the neighboring land properties are determined [2].

The following characteristics and parameters of the land property are determined through the settlement process:

- The specific purpose of the property, the eligible activities and the type of admissible construction in the property;

\footnotetext{
*Correspondence to: Gena Velkovska, Trakia University, Faculty of Economics - Stara Zagora city, Bulgaria,e-mail: gvelkovski@abv.bg
}

- The method of construction, which can be free, connected or complex (group);

- Depending on the height and number of stories of the building, the nature of construction;

- The construction lines, which by their nature play the role of restrictive lines, to which it can be built and of obligatory lines, to which it is obligatory to build;

- The values of the construction indicators: density (percentage) of construction of the land property, density (percentage) of utilization of the land property, the percentage of the minimum free (undeveloped) yard area and the percentage of the minimum obligatory landscaped yard area.

Construction as a technological process is preceded by regulation, but is also associated with the manifestations of the relevant property law. Based on his rights as the owner of the 
land property, the owner can claim to carry out all the eligible construction under the plan.

In a foreign land they have the right to build the persons determined by law [5]. These are, first of all, the persons in whose favor a superficies, respectively a right of standing, superstructure and extension have been established [5].

The owners of regulated land properties, for which detailed development plans provide for the construction of sites - public property of the state and municipalities, have the right, as an exception, to build buildings to meet urgent housing, professional, business needs. These constructions are called temporary constructions. Temporary constructions may also be permitted in regulated land properties, for which a new way or character of construction has been established or a construction ban has been imposed. Temporary constructions are allowed only once in a regulated land property, provided that the new construction is not expected to start in the next three years.

\section{MATERIAL AND METHODS}

The regulation of territories and land properties is an important and necessary legal procedure in the organization of the territory [1]. The mechanism by which this procedure is carried out is the detailed spatial planning.

How does this mechanism work?

The detailed development plans regulate:

- streets;

- neighborhoods;

- land properties.

The settlement process is aimed at subsequent construction and for other needs without construction.

What is the difference between unregulated territory and regulated land property?

Unregulated territory is a territory in which the land properties are not regulated by a detailed development plan.

Regulated land property (regulated property) is a land property for which a detailed development plan defines boundaries, access from a street, road or alley, specific purpose and mode of development.

There are specific differences in the regulation of streets, neighborhoods and the regulation of land.
Streets and neighborhoods are regulated by street regulation lines.

Land properties are regulated by:

- street regulation lines, which determine the border with the adjacent street (face of the property);

- internal regulation lines, which determine the borders with the neighboring properties (side and to the bottom of the property), under the conditions of art.16 or 17 of the Spatial Planning Act.

The texts of Art.16 are related to some specifics, referring to the content of the detailed development plans for territories with unregulated land properties, as well as for territories with not applied first regulation under a previous development plan. With the text of para. 1 of the indicated art. 16 imposes the legal necessity and the legal requirement to determine the necessary areas for construction of the objects of the social infrastructure public property of the green areas, united in a green system, and of the common networks and facilities of the technical infrastructure. For this purpose, with the entry into force of the plan, the property owners transfer in favor of the municipality a percentage of the area of their properties determined by the plan, but not more than 25 percent.

Al. 2 of Article 16 approves as a basis of the detailed development plan a cadastral map, approved by the order of the Law for the cadastre and the property register.

In para. 3 , a specific legal norm shall indicate the principle of determining the person and the area of the newly formed regulated properties. The face and the area of the newly formed regulated properties, their specific purpose, the nature and the manner of their construction are determined by the very detailed development plan. This is proof of the important role of the detailed development plan as a major mechanism in the regulation of territories and land properties.

What happens to the owners of the land properties in the presence of a plan for regulated land properties?

First, the municipality assigns an equivalent regulated property (properties) to each real estate owner, taking into account the location of the properties in the area, but not their exact cadastral boundaries. Second, when the 


\section{VELKOVSKA G.}

property falls into different development zones, the newly formed regulated property is provided in the area in which the property had a predominant location.

Third, the regulated properties have a market value not less than the market value of the properties before their settlement, which is proved by a decision of the commission under Article 210.

This is a commission appointed by the mayor of the municipality, which carries out the procedures for preparing assessments and determining the amount and payment of benefits in cases expressly provided by law are carried out at market prices.

The mayor orders ex officio or on the basis of a request of the interested persons the determination of compensations or assessment by the commission.

The decision of the commission shall be communicated to the parties by the order of the Administrative Procedure Code. They can appeal it in the prescribed manner.

Fourth, the owners of land properties acquire ownership of the newly formed land properties regulated by the plan, and the municipality acquires ownership of the ceded parts from the date of entry into force of the plan.

Fifth, for the acquisition of the ownership of each separate regulated land property, the mayor of the municipality or a person authorized by him issues an order with precise individualization of the property.

Within 7 days from the entry into force of the order, a copy of it shall be sent to the Registry Office, and a copy of the approved plan - to the Agency for Geodesy, Cartography and Cadastre - for official entry in the property register and entry in the cadastre.

Sixth, mortgages imposed on land properties before their settlement are transferred entirely to newly created regulated land properties. The municipality acquires the ceded parts of the land properties without real encumbrances.

An important feature is the legal possibility for the creation of a plan for street regulation by decision of the municipal council.

In para. 7 of Art. 16 of the Spatial Planning Act states that for territories with unregulated land properties, as well as for territories with unimplemented first regulation under a previous zoning plan by decision of the municipal council instead of a detailed zoning plan may be created a plan for street regulation and properties for objects of public property under Art. 110, para. 1, item 2 of the Spatial Planning Act.

Within the meaning of Art. 110, para. 1, item 2 of the Spatial Planning Act, the plan for regulation - PR (plan for regulation of streets and land properties without building regime); the plan for regulation can be a plan for street regulation - RMP (plan for regulation only of streets and land properties for objects of public property).

In Art. 17 of the Spatial Planning Act, certain specifics are indicated, except for the cases under Art. 16.

First, a detailed development plan for a settlement or part of it regulates previously unregulated land properties, as their internal regulation lines coincide with the property boundaries.

Second, with a detailed zoning plan for regulation, the following can be regulated:

- available unregulated land properties in order to form more independent regulated land properties;

- land properties, the sizes of which do not meet the requirements of art. 19 of the Spatial Planning Act, in order to authorize them with parts of neighbouring properties;

- neighbouring unregulated land properties for creation of co-owned regulated land properties. These are the following legal standards, reflected in Art. 19 para. 1, 2, 3, 4, 5, 6, 7, relating to the size of the properties and other parameters, namely:

First, when settling land for low-rise housing, vacant or connected in two properties, the following dimensions are observed:

- in cities - at least $14 \mathrm{~m}$ face and 300 sq. m surface;

- in the resort settlements and settlement formations and in the resort zones of the settlements - at least $16 \mathrm{~m}$ face and 500 sq.m surface;

- in the villa zones - at least $18 \mathrm{~m}$ face and 600 sq.m surface;

- in the villages or parts of them with predominant flat terrain - at least $16 \mathrm{~m}$ face and 500 sq.m surface, and in specific terrain and economic conditions, as well as on main 


\section{VELKOVSKA G.}

streets - at least $14 \mathrm{~m}$ face and 300 sq.m surface;

- in the villages or parts of them with predominantly steep terrain - at least $12 \mathrm{~m}$ face and 250 sq. $\mathrm{m}$ surface.

Second, by a decision of the municipal council on the basis of a conclusion of the municipal expert council the villages or the parts of them with predominant flat or steep terrain are determined.

Third, the minimum sizes of regulated low-rise properties (face and surface) defined above may be reduced by a maximum of one-fifth depending on the economic, technical or terrain conditions or in relation to the situation of the existing solid buildings, when this does not worsen the conditions for appropriate construction, based on the conclusion of the municipal expert council.

Fourth, in case of division of the land properties by the above-mentioned sizes, the actually detached parts cannot be smaller than the minimum ones defined in the Spatial Planning Act, reduced by at most $1 / 5$.

Fifth, when settling land in neighbourhoods for medium and high housing construction, for low-rise construction in more than two properties for construction with social housing or for other specific construction, the size of the properties is determined by the detailed development plan itself, without comply with the above rules.

Sixth, when settling land within the settlements for non-residential construction or for other needs without construction, their size is determined by a detailed zoning plan, in accordance with the sanitary-hygienic and fire safety requirements and the relevant zoning rules and regulations.

Seventh, the outlines of streets, squares and regulated properties and their dimensions, as well as the construction of properties in settlements or in their parts of historical, archaeological, ethnographic or architectural significance are established by the most detailed development plan so as to preserve the historical and the architectural values, the environment, the characteristic volumetricspatial and architectural-artistic image and the valuable woody vegetation.

In these cases the interested owners submit an application to the municipality and a preliminary contract for transfer of ownership with notarized signatures as the ideal parts of the co-owners in the formed co-owned regulated land properties are determined by the contract itself.

Construction is permitted upon presentation of a final contract.

Copies of the detailed development plans that have entered into force shall be sent ex officio by the municipality to the Agency for Geodesy, Cartography and Cadastre.

An important legal requirement for regulated land properties is that they must have a face (exit) to a street, a road or, exceptionally, an alley in a park.

Another important feature of the land properties regulated by a detailed zoning plan is that the regulation lines with which these properties are regulated become boundaries of the properties when the detailed zoning plan is applied with regard to the regulation.

With a detailed development plan under the already mentioned art. 16 and Art. 17 of the Spatial Planning Act, only land properties that have not been regulated by a previous detailed development plan are regulated. Here, too, there is an important legal standard, namely: once regulated land properties are not subject to subsequent regulation except in the cases provided for in the Spatial Planning Act.

Only streets and neighborhoods can be regulated with a subsequent detailed development plan, without changing the boundaries between the landed properties.

How can the boundaries of regulated land properties be changed?

The boundaries of regulated land properties can be changed with a regulation plan only with the consent of their owners. This consent must be expressed with an application and a preliminary contract for transfer of ownership with notarized signatures.

When a regulation plan changes the boundaries of regulated land properties - state property, the above contract is concluded at market prices by the regional governor in writing.

These contracts are an important basis for permitting construction in regulated land properties. Construction in regulated land properties, the boundaries of which are 
changed by the regulation plan, is allowed after submission of a final contract.

When a regulation plan changes the boundaries of regulated land properties - municipal property, the above contract is also concluded at market prices, but by the mayor of the municipality, also in writing.

Copies of the entered into force amendments to the detailed development plans shall be sent ex officio by the municipality to the Agency for Geodesy, Cartography and Cadastre after presentation of the indicated final contracts.

The entry into force of a regulatory plan shall be preceded by an order approving it. The regulation plan, which changes the boundaries between regulated land properties, enters into force with the issuance of the order and is communicated to the applicants accordingly.

If, as a result of the amendment of the regulation plan, the construction plan for the respective regulated land properties is in contradiction with the current development rules and regulations, construction in these properties shall not be permitted.

The amendment to the regulatory plan may be rejected. The body that refuses this amendment is the Mayor of the municipality. The amendment is rejected in the following cases: -when the draft amendment envisages the creation of a legally inadmissible location of existing buildings or of permitted constructions;

- when the draft amendment envisages the creation of regulated land properties with face and surface, which are below the minimum established by law for the nature and manner of construction determined by the construction plan of these properties.

What are the main characteristics of the land properties, regulated for construction with a detailed development plan, which characteristics are determined by this detailed development plan?

These are:

- the specific purpose, the eligible activities and the eligible construction;

- the maximum building density; (building density is the ratio of the sum of the built-up areas of the main and additional construction to the area of the regulated land property, expressed as a percentage. Building density can be determined in total for a neighbourhood, development territory or zone, as well as for parts).

- the maximum intensity of construction (intensity of construction of the regulated land property is the ratio of the unfolded built-up area to the area of the regulated property, expressed in absolute number. parts thereof);

- the minimum free yard area (free yard area is the difference between the area of the regulated land property and the built-up area. The open usable terraces on the underground floor, as well as the green areas are considered as such area);

- the minimum obligatory landscaped yard area;

- the manner and nature of construction (method of construction is the location of the buildings and structures of the main and additional construction in the regulated land properties);

- the construction lines (external construction line is the construction line to the street. It may coincide with the street regulation line or be at a distance from it inwards in the regulated land property;

internal construction line is the construction line to neighboring regulated land properties or to neighboring buildings. The internal construction lines are lateral and to the bottom of the regulated land property).

It should be noted here that some types of detailed development plans may contain only a part of the indicated characteristics (indicators).

\section{RESULTS AND DISCUSSION}

The analysis of the legislation dealing with the issues of regulation and construction of land properties, as well as the developments of some authors in this regard [3-5], outline some imperfections of the legal framework, namely: - the legal impossibility for secondary regulation of the land properties, as a mass legal norm; the legislation provides for a detailed zoning plan to regulate only land properties that have not been regulated by a previous detailed zoning plan;

- complicated technological and legal procedures for the amendment of a regulation plan, which amendment is authorized by the mayor of the municipality;

- imperfections resulting from the dynamic changes in the legislation, which regulates issues related to the cadastre as a basis for the preparation of detailed development plans; 


\section{VELKOVSKA G.}

- imperfections related to the expropriation procedures of land properties and the compensation of their owners;

- the impossibility to appeal the general development plans, regardless of their defects and from there - the transfer of these defects on the detailed development planning, respectively on the efficient and smooth running of the processes of settlement and construction of land properties.

\section{CONCLUSIONS}

In order to fulfill its role in the process of regulation of land properties and, accordingly, to provide the necessary conditions in which to implement the various types of construction on the territory, the legislation in these two areas needs to be constantly improved in order to update it in a timely manner. At this stage, the following directions for the elimination of the above-mentioned imperfections are urgent:

First, to regulate the possibility and facilitate the procedure for the implementation of secondary regulation of land properties;

Second, to work out a legal mechanism for regulating the construction of regulated land properties, the boundaries of which are changed by the regulation plan;

Third, to regulate the possibilities for change in the regulation plan for land properties that have a face and area below the minimum regulated at this stage.

These and other similar regulatory improvements will also help solve a number of accumulated problems in the territories and their sustainable development.

\section{REFERENCES}

1. Velkovska, G., Spatial planning. Regulation and construction - CD, ed. "Valdes - BB GV", S., 2014, pp.6;

2. Spatial Planning Act, in force since 31.03.2001, amended SG. issue 1 of January 2, 2001, amended and ext. SG. issue 41 of 21 May 2019, supplement SG. issue 44 of June 4, 2019, supplement. SG. issue 62 of August 6, 2019;

3. Kalinkov, K., Urbanism - Theories, models, plans and indicators, 2004, IC-Gea-PrintVarna, p.117;

4. Kalinkov, K., Urban Planning - Theories and Models for Urban Development \& Spatial Planning, 2010, Gea-Print-Varna Publishing House,p.388;

5. Kovachev, At., Kalinkov, K., THEASURUS, 2011, IC-Gea-Print-Varna, p.389;

6. http: // www.lex.bg. 